\title{
Improvement of Mechanical and Electrical Properties on the Sintered Ni-50 mass\% Cr Alloys by HIP Treatment
}

\author{
Shih-Hsien Chang ${ }^{1, *}$, Jing-Chi Chen ${ }^{1}$, Kuo-Tsung Huang ${ }^{2}$ and Jhewn-Kuang Chen ${ }^{1}$ \\ ${ }^{1}$ Department of Materials and Mineral Resources Engineering, National Taipei University of Technology, \\ Taipei 10608, Taiwan, R. O. China \\ ${ }^{2}$ Department of Auto-Mechanics, National Kangshan Agricultural Industrial Senior High School, \\ Kaohsiung 82049, Taiwan, R. O. China
}

This study investigated Ni-50 mass\% Cr alloys produced by the vacuum sintering and hot isostatic pressing (HIP) of powder metallurgy technology. The experimental results showed that the relative density of $\mathrm{Ni}-50$ mass $\% \mathrm{Cr}$ alloys reached $98.67 \%$, the apparent porosity decreased to $1.33 \%$, transverse rupture strength (TRS) increased to $454.29 \mathrm{MPa}$ and electrical resistivity decreased to $4.284 \times 10^{-4} \Omega \cdot \mathrm{cm}$ after $1345^{\circ} \mathrm{C}$ sintering for $1 \mathrm{~h}$. Meanwhile, laminar eutectic precipitations appeared in the sintered Ni-50 mass $\% \mathrm{Cr}$ alloys. In addition, the relative density increased to $99.73 \%$, the apparent porosity decreases to $0.27 \%$ and TRS was obviously enhanced to $1181.4 \mathrm{MPa}$ after $1260^{\circ} \mathrm{C} 175 \mathrm{MPa}$ $4 \mathrm{~h}$ HIP treatment. Moreover, the electrical resistivity decreased to $3.346 \times 10^{-4} \Omega \cdot \mathrm{cm}$ after the optimal HIP treatment. This study showed that the HIP process is effective in eliminating internal pores and improving the mechanical and electrical properties of the sintered $\mathrm{Ni}-50 \mathrm{mass} \% \mathrm{Cr}$ alloys, thus obtaining the high density and optimum properties of the sintered materials. [doi:10.2320/matertrans.M2013018]

(Received January 11, 2013; Accepted March 19, 2013; Published May 25, 2013)

Keywords: nickel-50 mass\% chromium alloy, vacuum sintering, hot isostatic pressing (HIP), transverse rupture strength (TRS), electrical resistivity

\section{Introduction}

The advantages of the application of nickel-chromium $(\mathrm{Ni}-\mathrm{Cr})$ alloys as structural and device materials have been recognized for decades. ${ }^{1)}$ Nickel base alloys, which are commonly called high temperature materials, are used for turbine blades, structural materials for nuclear reactor, and also for welding and brazing purposes. ${ }^{2)}$ The presence of chromium in these alloys strengthens the nickel matrix and by forming a stable adherent oxide considerably, then increases the hot corrosion resistance. The excellent properties of $\mathrm{Ni}-\mathrm{Cr}$ alloys are due to their complex composition. ${ }^{1,2)}$ Their good mechanical properties and low cost dramatically increased their popularity in the last decades. ${ }^{3)}$ In addition, $\mathrm{Ni}-\mathrm{Cr}$ film has a good electrical resistivity, low sheet resistance and temperature coefficient of resistance, as well as excellent anti-adhesion properties. Therefore, various compositions of the $\mathrm{Ni}-\mathrm{Cr}$ alloys have been widely used in the sputtering of thin films, micro-electro components, panel display boards and optical storage media materials., ${ }^{4,5)}$

Powder metallurgy $(\mathrm{P} / \mathrm{M})$ methods offer two different types of materials with the objective of achieving higher strength, hardness and wear resistance etc. Conventional sintered P/M-parts usually have more than 5\% porosity. Enhanced sintering techniques can be applied to obtain higher densities and improved porosity in the sintered parts. ${ }^{6,7)}$ Powder metallurgy, such as hot isostatic pressing (HIP) can be used for upgrading casting, packing pre-sintered components, and interfacial bonding; it involves the simultaneous application of high pressure and elevated temperature in a specially constructed vessel. HIP can be applied to a wide range of metals, alloys and ceramics. ${ }^{8-11)}$

Recently, the melting technology and the sintering methods of $\mathrm{Ni}-\mathrm{Cr}$ alloys have been remarkably developed.

*Corresponding author, E-mail: changsh@ntut.edu.tw
Furthermore, it is possible to produce the sintered alloys with desirable composition. This research has triggered off our interesting in the sintered nickel-chromium alloys with a high content of chromium (50 mass \%). Therefore, this study produced $\mathrm{Ni}-50$ mass $\% \mathrm{Cr}$ alloys using the vacuum sintering and hot isostatic pressing techniques of powder metallurgy technology. Moreover, we carried out a series of experimental tests to explore the characteristics and effects of the different powder metallurgy processes on the $\mathrm{Ni}-$ 50 mass $\% \mathrm{Cr}$ alloys.

\section{Experimental Procedures}

In this study, 99.995\% (4N5) electrolysis nickel and 99.95\% (3N5) reduction chromium powders were mixed and pressed to produce the $\mathrm{Ni}-50$ mass\% $\mathrm{Cr}$ alloys. A Honeywell Microtrac X 100 laser was used to analyze the particle size of the powders. The surface shapes of the $\mathrm{Ni}$ and $\mathrm{Cr}$ powder particles are shown in Fig. 1. The morphology of the electrolysis nickel powder showed typical dendrite and feather shapes, and the mean size was about $10.8 \pm 0.5 \mu \mathrm{m}$, as shown in Fig. 1(a). The shape of the reduction chromium powder was irregular, without smooth undulating surface, as shown in Fig. 1(b). Meanwhile, the mean particle size was about $24.9 \pm 0.5 \mu \mathrm{m}$. Furthermore, the mean particle size of the $\mathrm{Ni}-50$ mass\% Cr alloys was about $32.8 \pm 0.5 \mu \mathrm{m}$ after $1 \mathrm{~h}$ of ball milling. The SEM photograph indicates that the particles are obviously cold welded due to mechanical alloying by ball milling (Fig. 1(c)).

The Ni-50 mass $\% \mathrm{Cr}$ powders were put in an alloy steel mold $(6 \times 6 \times 40 \mathrm{~mm})$ and a vertical force of the hydraulic press was applied to the mold during the forming process. In this study, the forming pressure was controlled at $207 \mathrm{MPa}$ for $10 \mathrm{~min}$; the vacuum degree of sintering furnace (Dengyng Instruments, Co., Ltd.) was maintained at $1.33 \times 10^{-9} \mathrm{MPa}$, and the soaking time was $60 \mathrm{~min}$. According to the $\mathrm{Ni}-\mathrm{Cr}$ 

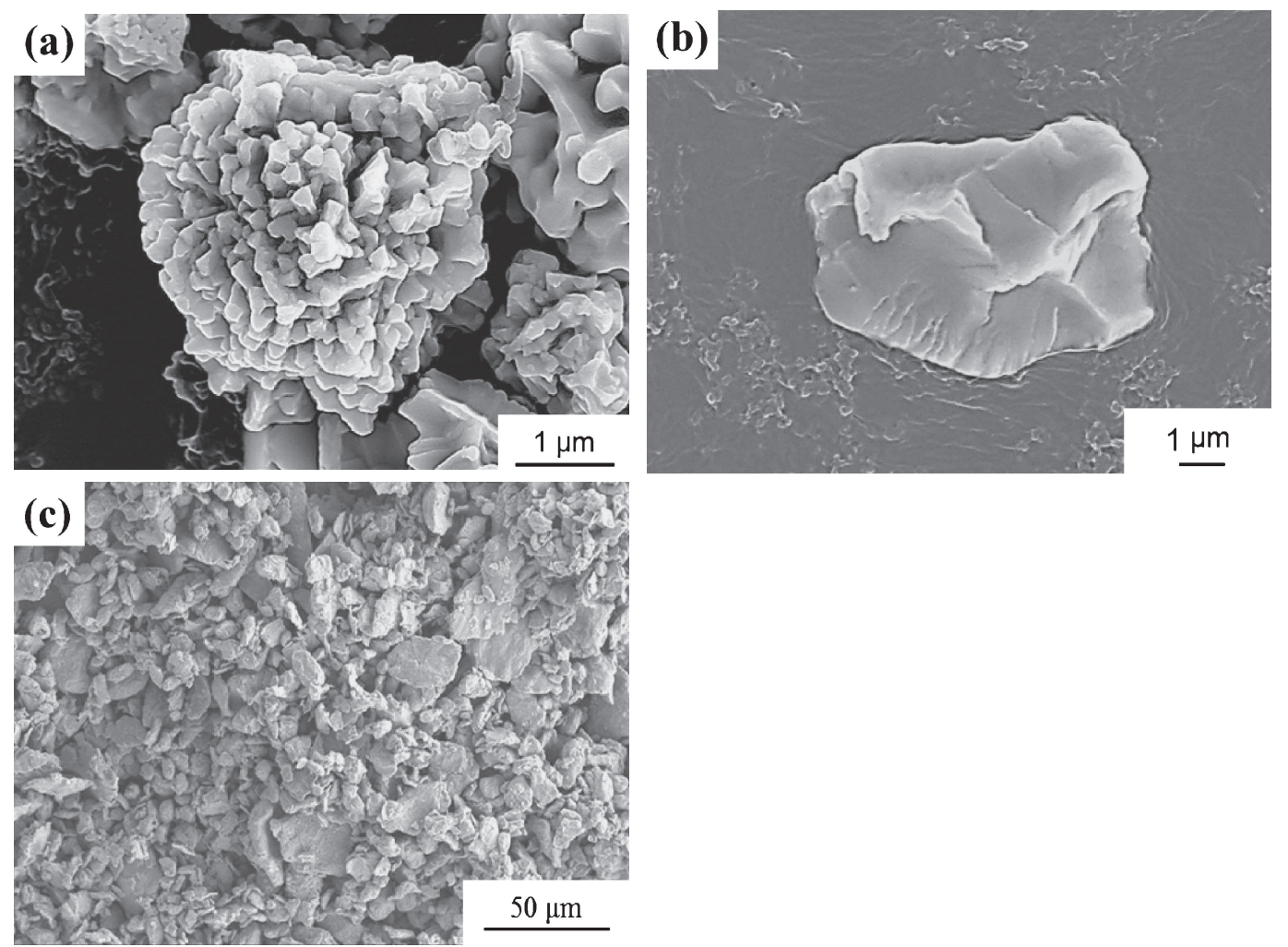

Fig. 1 SEM photographs of the surface morphology: (a) electrolysis Ni powders, (b) reduction Cr powders and (c) Ni-50 mass\% Cr alloy powders after $1 \mathrm{~h}$ ball mixing.

binary alloy phase diagram, ${ }^{12}$ ) the sintering temperature was set at 1325 and $1345^{\circ} \mathrm{C}$. All of the optimum sintered specimens were subjected to the following HIP treatment after the sintering process. The HIP was conducted using the equipment of Flow Autoclave Pressure System that was equipped with uniform rapid cooling, saved cycle time and increased productivity. ${ }^{13}$ )

To evaluate the microstructure, mechanical and electrical properties of the $\mathrm{Ni}-50$ mass $\% \mathrm{Cr}$ alloys after the various $\mathrm{P} / \mathrm{M}$ processes; the porosity, hardness, transverse rupture strength (TRS) tests, X-ray diffraction (XRD, Rigaku DMX$2200)$, electrical resistivity and microstructure inspections were performed, respectively. Microstructural features of the specimens were examined by optical microscopy (OM, Nikon Eclipse Lv150) and scanning electron microscopy (SEM, Hitachi-S4700). The relative density and porosity tests followed the ASTM B311-08 and C830 standards. In addition, the hardness of the sintered specimens was measured by Rockwell indenter (HRB, Indentec 8150LK) with loading of $100 \mathrm{~kg}$, which complied with the ASTM B163-11standard. The Hung Ta universal material test machine (HT-9501A) with a maximum load of 25 tons was used for the TRS tests (ASTM B528-05). The electrical performance of the Ni-50 mass\% Cr alloys was evaluated by four-point resistance value measurements. A Napson RT-7 four-point probe was used to measure sheet resistance. In addition, electrical resistivity was calculated according to the following formula: ${ }^{14)}$

$$
\rho=\frac{V}{I} C \cdot t \quad(\mathrm{~m} \Omega-\mathrm{cm})
$$

where the $\rho$ is electrical resistivity, $V$ is voltage, $I$ is current, $C$ is a constant, and $t$ denotes the thickness of the test sheet.

\section{Results and Discussion}

Figure 2 shows the OM morphology observations of $\mathrm{Ni}-50$ mass\% $\mathrm{Cr}$ alloys after 1325 and $1345^{\circ} \mathrm{C}$ sintering treatments. Figure 2(a) clearly shows that many closed pores still remained in the grain boundaries of $\mathrm{Ni}-50$ mass\% $\mathrm{Cr}$ alloys after sintering at $1325^{\circ} \mathrm{C}$ for $1 \mathrm{~h}$; the grain size was relatively smaller than that of the specimen sintered at $1345^{\circ} \mathrm{C}$ for $1 \mathrm{~h}$, as shown in Fig. 2(b). Figure 2(b) shows that the porosity obviously decreased as the temperature was raised to $1345^{\circ} \mathrm{C}$. Because the sintering temperature $\left(1345^{\circ} \mathrm{C}\right)$ was close to the eutectic point of the $\mathrm{Ni}-\mathrm{Cr}$ alloy, it was possible to reach the liquid phase sintering temperature of the Ni-50 mass\% Cr alloys. As a result, almost no closed pores existed in the microstructure. In addition, it was also found that the eutectic precipitations appeared in the matrix, showing a typical eutectic microstructure in the $\mathrm{Ni}-\mathrm{Cr}$ alloys. As the temperature rapidly dropped, the $\mathrm{Cr}$-rich and Ni-rich phases experienced continuous precipitation and spread to both sides of the eutectic precipitations (as seen in Fig. 3), respectively. The result agreed with the previous literature. ${ }^{15)}$

Observations of the SEM morphology of Ni-50 mass\% $\mathrm{Cr}$ alloys from the $1345^{\circ} \mathrm{C} 1 \mathrm{~h}$ sintering treatment revealed that the specimen having the laminar eutectic precipitates was completely sintered, as shown in Fig. 3. Furthermore, to confirm the structure of the matrix and precipitations (areas A and B), a semi-quantitative EDS analysis was performed. As indicated in Table 1, the elements in region A were $\mathrm{Cr}$ 

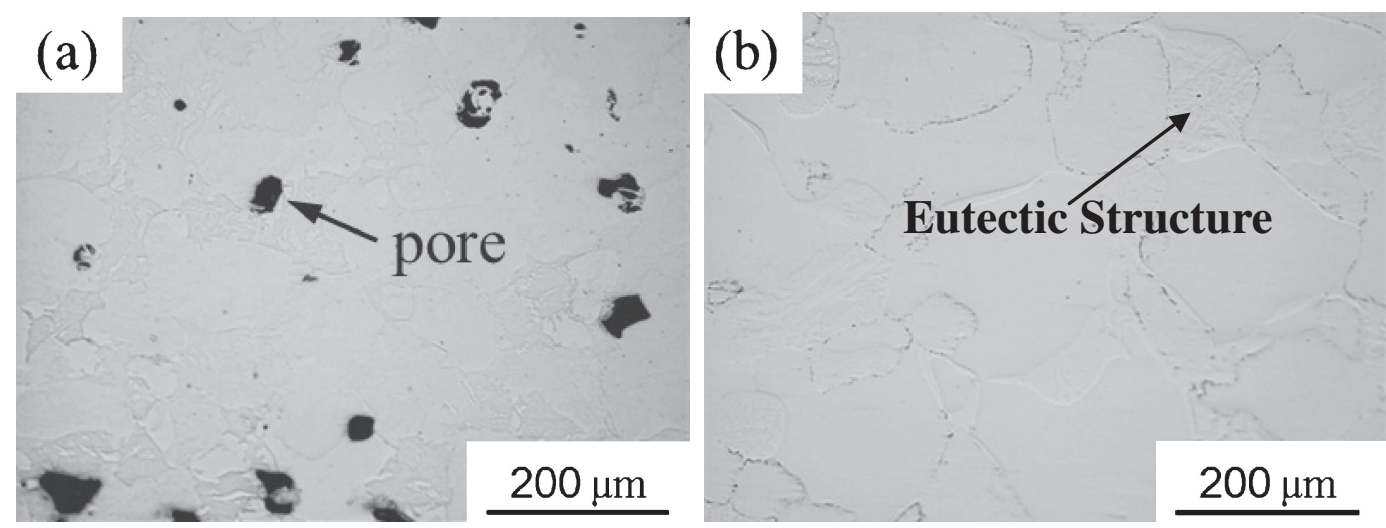

Fig. 2 OM morphology observations of Ni-50 mass $\% \mathrm{Cr}$ alloys by various sintering temperature treatments (a) $1325^{\circ} \mathrm{C}$, and (b) $1345^{\circ} \mathrm{C}$.

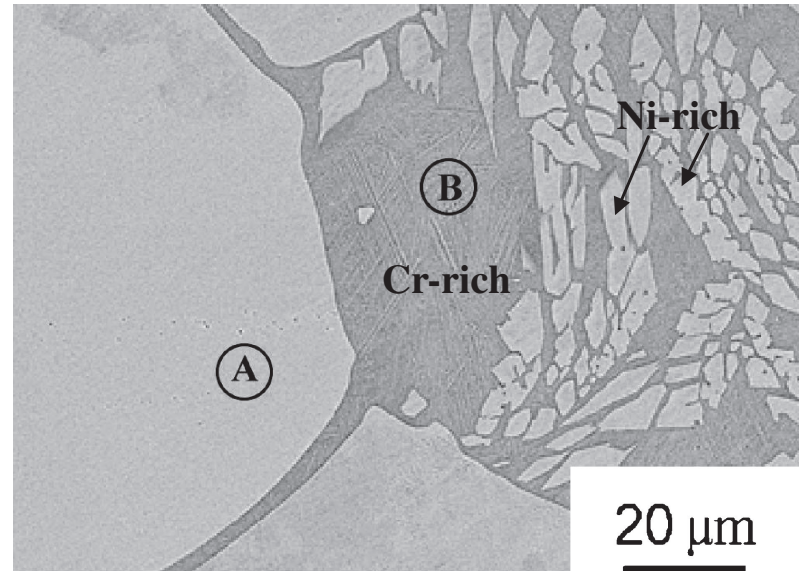

Fig. 3 SEM morphology observations of $\mathrm{Ni}-50$ mass\% $\mathrm{Cr}$ alloys by $1345^{\circ} \mathrm{C} 1 \mathrm{~h}$ sintering treatment.

Table 1 EDS analysis results of area A and B in Fig. 3.

\begin{tabular}{cccc}
\hline \multicolumn{2}{c}{ Elements } & Nickel & Chromium \\
\hline \multirow{2}{*}{ Area A } & Mass\% & 52.16 & 47.84 \\
& Atomic\% & 49.12 & 50.88 \\
\hline \multirow{2}{*}{ Area B } & Mass\% & 31.16 & 68.84 \\
& Atomic\% & 28.61 & 71.39 \\
\hline
\end{tabular}

at 47.84 mass $\%$ and $\mathrm{Ni}$ at 52.16 mass $\%$. Significantly, the weight percent was close to the percentage of the original $\mathrm{Ni}-50$ mass\% $\mathrm{Cr}$ alloy powders. On the other hand, the precipitate area of region $\mathrm{B}$ (Cr-rich phase) had $\mathrm{Cr}$ element at 68.84 mass $\%$ and $\mathrm{Ni}$ element at 31.16 mass $\%$. According to the Ni-Cr binary alloy phase diagram, ${ }^{12}$ the $\mathrm{Cr}$-rich phase was very close to the chromium percentage composition of the eutectic isotherm. Therefore, it was reasonable to suggest that the laminar precipitates were the solidified precipitates of the $\mathrm{Ni}-\mathrm{Cr}$ eutectic point.

In this study, the relative density of the $\mathrm{Ni}-50$ mass $\% \mathrm{Cr}$ alloys was about $90.93 \%$ after the $1325^{\circ} \mathrm{C} 1 \mathrm{~h}$ sintering process. However, a higher relative density (98.67\%) was achieved as the sintering temperature increased to $1345^{\circ} \mathrm{C}$. Owing to the sintering temperature $\left(1345^{\circ} \mathrm{C}\right)$ approaching the eutectic point of the $\mathrm{Ni}-\mathrm{Cr}$ binary alloy, the liquid nickel quickly filled up the pores between the chromium grains due to the liquid phase sintering (LPS) effects. Meanwhile, the
Table 2 Comparison of the various properties of $\mathrm{Ni}-50$ mass $\% \mathrm{Cr}$ alloy by different sintering temperature treatments.

\begin{tabular}{cccccc}
\hline $\begin{array}{c}\text { Sintering } \\
\text { temperature } \\
\left({ }^{\circ} \mathrm{C}\right)\end{array}$ & $\begin{array}{c}\text { Relative } \\
\text { density } \\
(\%)\end{array}$ & $\begin{array}{c}\text { Apparent } \\
\text { porosity } \\
(\%)\end{array}$ & $\begin{array}{c}\text { TRS } \\
(\mathrm{MPa})\end{array}$ & $\begin{array}{c}\text { Hardness } \\
(\mathrm{HRB})\end{array}$ & $\begin{array}{c}\text { Electrical } \\
\text { resistivity } \\
\left(\times 10^{-4} \Omega \cdot \mathrm{cm}\right)\end{array}$ \\
\hline 1325 & 90.93 & 9.07 & 232.23 & 59.60 & 4.691 \\
1345 & 98.67 & 1.33 & 454.29 & 103.17 & 4.284 \\
\hline
\end{tabular}

particles and grains experienced the rearrangement, and the result was consistent with our previous findings. ${ }^{7,16)}$ Table 2 shows that the liquid phase sintering was effective in achieving a high density in the sintered materials. Besides, the apparent porosity of the $\mathrm{Ni}-50$ mass $\% \mathrm{Cr}$ alloys tended to decrease as the sintering temperature increased. A lower apparent porosity $(1.33 \%)$ also appeared after sintering at $1345^{\circ} \mathrm{C}$ for $1 \mathrm{~h}$.

Table 2 also shows the TRS value of the Ni-50 mass\% $\mathrm{Cr}$ alloys as $232.23 \mathrm{MPa}$ after the $1325^{\circ} \mathrm{C} 1 \mathrm{~h}$ sintering treatment. As the sintering temperature increased, the chromium content in the nickel-rich phase increased. Therefore, the solid-solution strengthening effect was more evident. ${ }^{17)}$ When the temperature increased to $1345^{\circ} \mathrm{C}$, the more suitable liquid phase sintering led to a rapid decrease in the closed pores, and the relative density was enhanced (98.67\%). Although the high-temperature coarsening phenomenon of the grain size appeared in the $1345^{\circ} \mathrm{C}$ sintered specimen (as seen in Fig. 2(b)), it was reasonable to suggest that the solidsolution strengthening of the chromium atoms solid-solution in the nickel-rich phase was effective in improving rupture resistance. Consequently, the sintered specimens $\left(1345^{\circ} \mathrm{C}\right)$ possessed higher bonding strength, which hindered the generation of the rupture mechanism, and the TRS value significantly increased to $454.29 \mathrm{MPa}$.

Table 2 lists that, the hardness results from the 1325 and $1345^{\circ} \mathrm{C}$ sintering of $\mathrm{Ni}-50$ mass\% Cr alloys were HRB 59.6 and HRB 103.17, respectively. The results were further compared with the relative density, which showed a positive relationship between the hardness and the relative density. The hardness was significantly enhanced as the sintering density increased. The literature also indicates that decreasing the porosities of sintered materials effectively enhances the plastic deformation resistance and hardness. ${ }^{6,7)}$ This result agreed with our findings. 

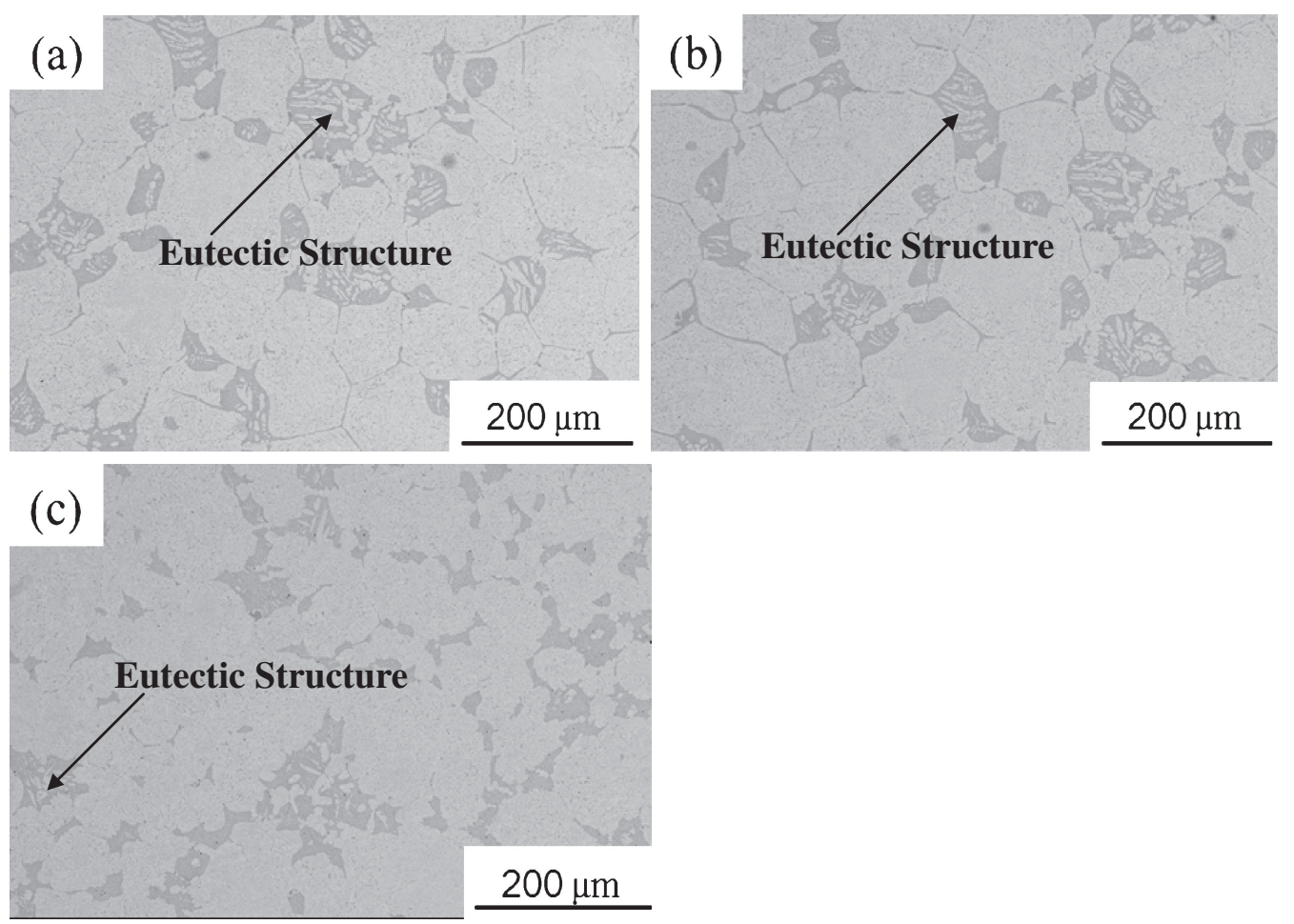

Fig. 4 SEM morphology observations of sintered Ni-50 mass $\%$ Cr alloys by different temperature of HIP treatments (a) $1200^{\circ} \mathrm{C}$ HIP, (b) $1230^{\circ} \mathrm{C}$ HIP and (c) $1260^{\circ} \mathrm{C}$ HIP.

Generally, the mean free path of the electrons is proportional to the relaxation time. A decrease in the mean free path of the electrons means "less moving", and the result is increased resistivity. ${ }^{7}$ ) The high density of the $1345^{\circ} \mathrm{C}$ sintered specimen resulted in an increase in the mean free path of the electrons, and the electrical resistivity of the $\mathrm{Ni}-50$ mass\% Cr alloys decreased $\left(4.691 \times 10^{-4} \rightarrow 4.284 \times\right.$ $\left.10^{-4} \Omega \cdot \mathrm{cm}\right)$. From the above results and discussion, it was reasonable to suggest that the optimal vacuum sintering process for the $\mathrm{Ni}-50$ mass $\% \mathrm{Cr}$ alloys required sintering at $1345^{\circ} \mathrm{C}$ for $1 \mathrm{~h}$. Therefore, to evaluate the effect of HIP treatment on the sintered $\mathrm{Ni}-50$ mass $\% \mathrm{Cr}$ alloys, the following experiments utilized $1345^{\circ} \mathrm{C} 1 \mathrm{~h}$ sintered specimens to explore the different HIP treatments.

Figure 4 shows the SEM morphology observations of the sintered $\mathrm{Ni}-50$ mass $\% \mathrm{Cr}$ alloys after various temperatures of HIP treatments. Because the $\mathrm{Ni}-50$ mass $\% \mathrm{Cr}$ alloys were close to the full liquid phase after $1345^{\circ} \mathrm{C} 1 \mathrm{~h}$ of sintering treatment, there was an insignificant variation in closed pores of the sintered specimens after various temperatures of HIP treatments, as shown in Fig. 4. It was reasonable to suggest that the high temperature and high pressure of the HIP treatment led to the decrease in internal closed pores, and that the closed pores of the specimens were almost completely eliminated. In addition, the specimens retained an obvious sintered eutectic structure after HIP treatments. There obviously existed a laminar eutectic structure in the HIP treated Ni-50 mass\% Cr alloys, as shown in Figs. 4(a)-4(c).

Figure 5 shows the XRD patterns of Ni-50 mass\% $\mathrm{Cr}$ alloys after as-sintering and various temperatures of HIP treatments. The XRD diffractions and their intensity depend on the crystal structure. ${ }^{7)}$ As compared with the XRD patterns of as-sintering and HIP processes, it was reasonable to

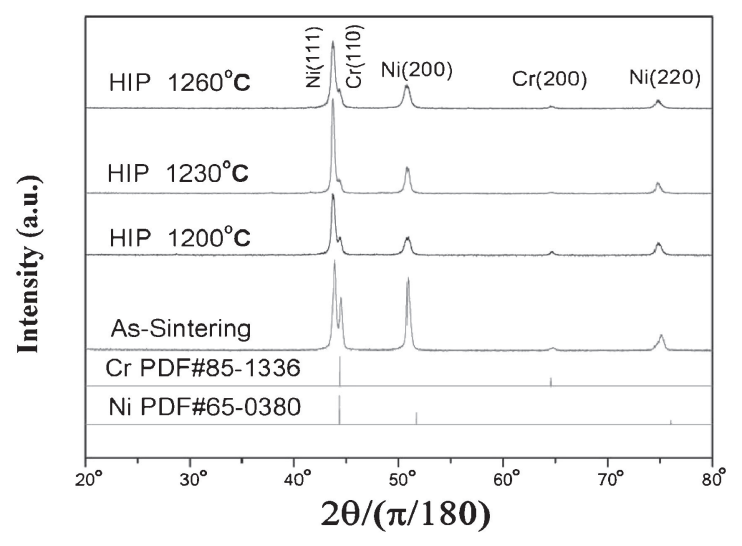

Fig. 5 XRD patterns of Ni-50 mass $\% \mathrm{Cr}$ alloys by as-sintering and different temperature of HIP treatments.

suggest that the $\mathrm{Ni}-50$ mass $\% \mathrm{Cr}$ alloys had better crystalline properties after HIP treatment. The major diffractions appeared in the Ni (111), Ni (200), Ni (220), Cr (110) and $\mathrm{Cr}$ (200) planes. It was observed that the intensity of $\mathrm{Ni}$ (111) first gradually increased and then decreased as the HIP temperature increased. Moreover, the diffraction peak of $\mathrm{Ni}$ shifted towards the low-angle as the HIP temperatures increased. It was reasonable to assume that the amount of $\mathrm{Cr}$ atoms solid-solution in the $\mathrm{Ni}$ phase of $\mathrm{Ni}-50$ mass $\% \mathrm{Cr}$ alloys increased as the HIP temperature increased. This meant that an increase of the $\mathrm{Cr}$ content in the Ni-rich phase resulted in a larger lattice constant, effectively increased the hardness and improved the transverse rupture strength of the alloys.

Figure 6(a) shows the relative density and apparent porosity of $\mathrm{Ni}-50$ mass $\% \mathrm{Cr}$ alloys after the as-sintering 

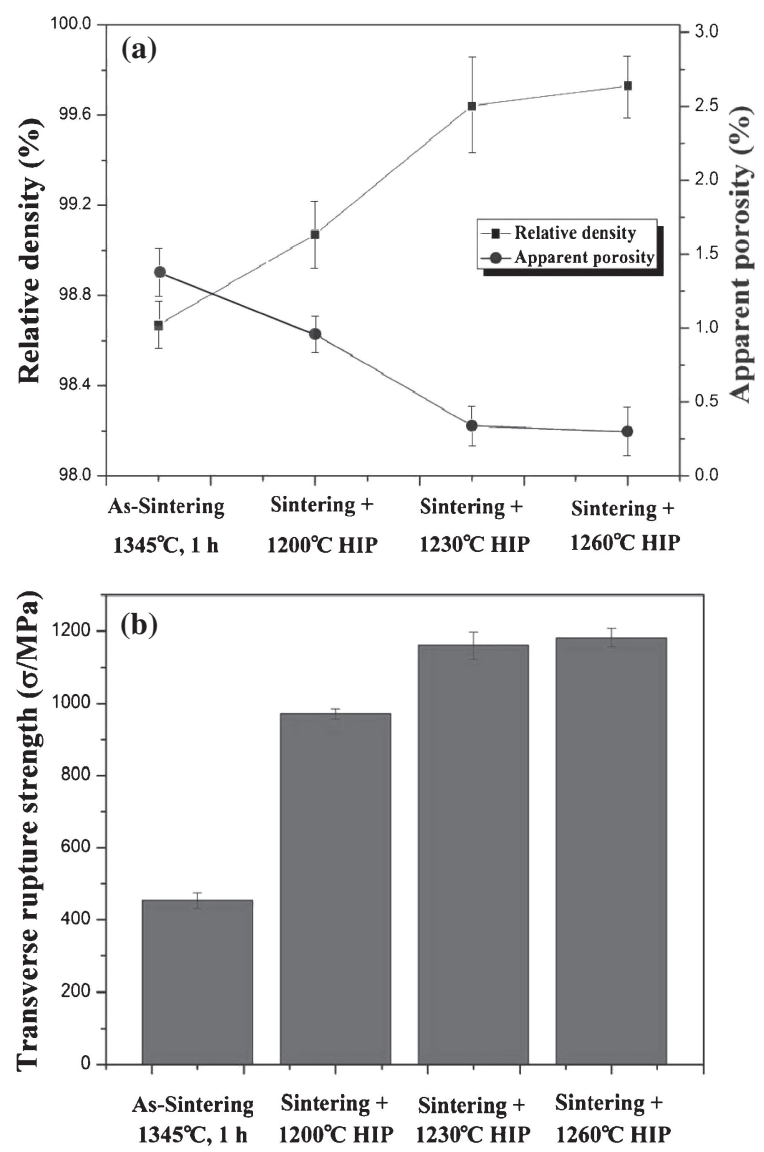

Fig. 6 Comparison of the (a) relative density and apparent porosity, (b) TRS tests of Ni-50 mass\% Cr alloys after as-sintering and different temperature of HIP treatments.

and different temperatures of HIP treatments. The relative density of the specimens could be significantly improved after the HIP treatments, and that tended to increase as the HIP temperature increased. In addition, the apparent porosity showed a steady decline and decreased to $0.27 \%$ after $1260^{\circ} \mathrm{C} 175 \mathrm{MPa} 4 \mathrm{~h}$ HIP treatment. A previous study indicated that the internal pores needed a greater diffusion distance to exhaust than the apparent porosity did; ${ }^{7)}$ thus, it was difficult to remove them solely by the diffusion mechanism. Therefore, the high-temperature diffusion and high-pressure closed-pores of the HIP principle played an important role in improving the densification of the HIPtreated specimens. Consequently, the HIP treatment was effective in removing the smaller closed pores of the materials, which resulted in the densification effect. This result also confirmed that the HIP treatment was advantageous in eliminating the internal pores and achieving the effect of full densification of $\mathrm{Ni}-50$ mass $\% \mathrm{Cr}$ alloys.

Figure 6(b) shows the TRS tests of the Ni-50 mass\% $\mathrm{Cr}$ alloys after the as-sintering and the different temperatures of HIP treatments. As indicated, the TRS values showed a rapid upward trend and then a slight increase as the HIP temperatures increased. The highest TRS value (1181.4 MPa) appeared in $1260^{\circ} \mathrm{C} 175 \mathrm{MPa} 4 \mathrm{~h}$ HIP-treated Ni-50 mass\% $\mathrm{Cr}$ alloys. The inner porosities of the specimens caused the stress concentration during the TRS tests, and resulted in the destruction of the specimens. Previous X-ray diffraction analysis also showed (as seen in Fig. 5) that the solid-

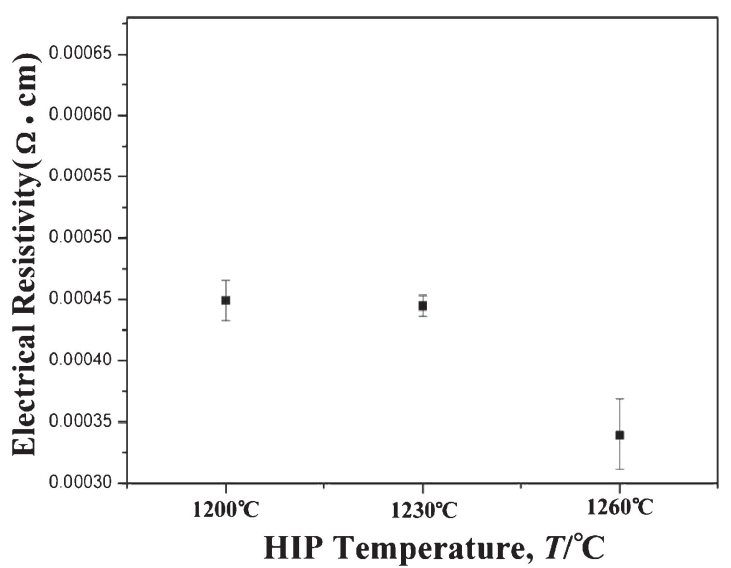

Fig. 7 Comparison of the electrical resistivity tests of $\mathrm{Ni}-50$ mass\% $\mathrm{Cr}$ alloys after different temperature of HIP treatments.

solution content of $\mathrm{Cr}$ atoms in the Ni phase of $\mathrm{Ni}-50$ mass $\%$ $\mathrm{Cr}$ alloys tended to increase as the HIP temperature increased. For these reasons, the HIP treatment enhanced the relative density and the solid-solution strengthening effect of the chromium atoms. As a result, the TRS value rapidly increased from $454.3 \mathrm{MPa}\left(1345^{\circ} \mathrm{C} 1 \mathrm{~h}\right.$ vacuum sintering) to $1181.4 \mathrm{MPa}\left(1260^{\circ} \mathrm{C} 175 \mathrm{MPa} 4 \mathrm{~h} \mathrm{HIP}\right)$. It was reasonable to suggest that the $1260^{\circ} \mathrm{C} 175 \mathrm{MPa} 4 \mathrm{~h}$ HIP treatment was the optimal process, as it effectively enhanced the mechanical properties of the sintered Ni-50 mass\% Cr alloys.

Figure 7 shows the electrical resistivity tests of $\mathrm{Ni}-$ 50 mass\% Cr alloys after HIP treatments under various temperatures. A previous study indicated that the electrical resistivity increased with an increase in porosity. ${ }^{7)}$ As Fig. 7 shows, the internal closed pores of the sintered specimens seemed to be significantly removed after HIP treatments. The electrical resistivity of $\mathrm{Ni}-50$ mass $\% \mathrm{Cr}$ alloys declined as the HIP treatment temperature increased to $1260^{\circ} \mathrm{C}$, as shown in Fig. 7. The result, when further compared with the relative density (Fig. 6(a)), showed that the electrical resistivity decreased to $3.346 \times 10^{-4} \Omega \cdot \mathrm{cm}$ and that the relative density increased to $99.73 \%$ after the optimal HIP treatment. The relationship between the relative density and the electrical properties of the $\mathrm{Ni}-50$ mass\% $\mathrm{Cr}$ alloys was also proven. Consequently, increasing the relative density was helpful in improving the electrical properties of the HIP-treated Ni50 mass $\%$ Cr alloys.

\section{Conclusions}

In this study, the relative density of the $\mathrm{Ni}-50$ mass $\% \mathrm{Cr}$ alloys reached $98.27 \%$, the hardness was enhanced to HRB 103.17 and TRS increased to $533 \mathrm{MPa}$ after $1345^{\circ} \mathrm{C}$ vacuum sintering for $1 \mathrm{~h}$; meanwhile, the electrical resistivity decreased to $4.284 \times 10^{-4} \Omega \cdot \mathrm{cm}$. Furthermore, enhancing the sintering temperature helped to increase the solid-solution strengthening effect of the $\mathrm{Ni}-50$ mass $\% \mathrm{Cr}$ alloys. By means of the XRD analysis, it was also proven that the $\mathrm{Cr}$ atom solid-solution in the Ni phase caused the diffraction peak of $\mathrm{Ni}$ to shift to the low angle dislocation.

The laminar eutectic structure clearly existed in the sintered and HIP-treated Ni-50 mass\% Cr alloys. In addition, 
the relative density of the sintered $\mathrm{Ni}-50$ mass $\% \mathrm{Cr}$ alloys reached $99.73 \%$, the apparent porosity decreased to $0.27 \%$, TRS increased to $1181.4 \mathrm{MPa}$ and the electrical resistivity decreased to $3.346 \times 10^{-4} \Omega \cdot \mathrm{cm}$ after $1260^{\circ} \mathrm{C} 175 \mathrm{MPa} 4 \mathrm{~h}$ HIP treatment. The microstructural analysis showed that the HIP treatment was effective in eliminating the internal closed pores of the sintered $\mathrm{Ni}-50$ mass $\% \mathrm{Cr}$ alloys, and that highdensity and high-strength $\mathrm{Ni}-50$ mass $\% \mathrm{Cr}$ alloys were acquired.

\section{Acknowledgments}

This research is supported by the ASSAB STEELS TAIWAN CO., LTD. The authors would also like to express their appreciations for Dr. Harvard Chen.

\section{REFERENCES}

1) Y. Harada, M. Ohmori, F. Yoshida and R. Nowak: Mater. Lett. 57 (2003) $1142-1150$.

2) A. M. Rana, A. F. Khan, A. Abbas and M. I. Ansari: Mater. Chem. Phys. 80 (2003) 228-231.

3) J. R. de O. Bauer, A. D. Loguercio, A. Reis and L. E. R. Filho: Dent. Mater. 20 (2006) 40-46.

4) I. H. Kazi, P. M. Wild, T. N. Moore and M. Sayer: Thin Solid Films 515
(2006) 2602-2606.

5) M. Danıșman and N. Cansever: J. Alloy. Compd. 493 (2010) 649653.

6) S. H. Chang, T. P. Tang, K. T. Huang and F. C. Tai: Powder Metall. 54 (2011) 507-512.

7) S. H. Chang, S. H. Chen and K. T. Huang: Mater. Trans. 53 (2012) 1689-1694.

8) M. Koizumi (ed.): Hot Isostatic Pressing-Theory and Applications, International Conference on Hot Isostatic Pressing, (Elsevier Applied Science, 1992) pp. 135-187.

9) S. H. Chang: J. Alloy. Compd. 486 (2009) 716-721.

10) T. Garvare: Proc. Int. Conf. Hot Isostatic Pressing-Lulea/15-17 June, (The Swedish Institute of Production Engineering Research, 1987) pp. 41-152.

11) S. H. Chang, S. C. Lee, T. P. Tang and H. H. Ho: Mater. Trans. 47 (2006) 426-432.

12) M. Hansen, R. P. Elliott, F. A. Shunk and Research Institute: Constitution of Binary Alloys, (New York, McGraw-Hill Book Co., 1958) p. 541.

13) Flow Autoclave System, Inc., Hot Isostatic Pressing Applications, (1996).

14) S. H. Chang, S. C. Lee, C. H. Tam, K. T. Huang, C. Liang and F. C. Tai: Powder Metall. 54 (2011) 325-330.

15) W. D. Callister and D. G. Rethwisch: Materials Science and Engineering: An Introduction, 7th Edition, (New York Wiley, 2007) pp. 276-282.

16) S. H. Chang, C. W. Lu and J. K. Chen: Int. J. Refract. Met. Hard Mat. 35 (2012) 70-75.

17) A. A. Al-Aql: Mater. Des. 24 (2003) 547-550. 